\title{
DESENVOLVIMENTO REGIONAL SOB A ÓTICA DO RECONHECIMENTO DA INDICAÇÃO GEOGRÁFICA: O CASE DO VALE DOS VINHEDOS, A PARTIR DA PERCEPÇÃO DOS ATORES SOCIAIS
}

REGIONAL DEVELOPMENT UNDER THE RECOGNITION VIEW OF THE GEOGRAPHICAL INDICATION: THE CASE OF VALE DOS VINHEDOS, BRAZIL, FROM THE PERCEPTION OF THE SOCIAL ACTORS

\section{Dieter Rugard Siedenberg}

Professor do Programa de Pós-Graduação em Desenvolvimento da Universidade Regional do Noroeste do Estado do Rio Grande do Sul, ljuí (RS), Brasil

Data de recebimento: $25-08-2015$ Data de aceite: 09-06-2017

\begin{abstract}
Aleteia Hummes Thaines
Doutoranda em Direito pela Universidade do Rio dos Sinos, professora da Universidade

Comunitária Regional de Chapecó, Chapecó (SC), Brasil

\section{Daniel Knebel Baggio}

Professor do Programa de Pós-Graduação em Desenvolvimento da Universidade Regional do Noroeste do Estado do Rio Grande do Sul, professor da Escola de Administração da Imed, Passo Fundo (RS), Brasil
\end{abstract}

\section{RESUMO}

Este artigo tem como objetivo analisar o desenvolvimento socioeconômico da área delimitada da região do Vale dos Vinhedos, localizada nos municípios de Bento Gonçalves, Garibaldi e Monte Belo do Sul, no estado do Rio Grande do Sul, a partir do reconhecimento da indicação geográfica e da percepção dos atores sociais envolvidos no processo. A pesquisa é qualitativa, descritiva, numa perspectiva histórica, a partir de um olhar dos próprios sujeitos envolvidos, isto é, produtores de vinhos, gestores das associações locais, representantes do poder público e técnicos que formataram o processo de reconhecimento da indicação de procedência dos vinhos. Os dados foram coletados a partir de questionários e entrevistas com os atores sociais mencionados. Os resultados proporcionaram, inicialmente, as concepções de desenvolvimento (local, endógeno), propriedade intelectual e indicações geográficas, a fim de fundamentar esta pesquisa, visando demonstrar o fomento do desenvolvimento da região do Vale dos Vinhedos por sua indicação de procedência. Além disso, esta pesquisa analisa o case dessa região, procurando evidenciar as implicações econômicas e sociais desse reconhecimento sobre o desenvolvimento do Vale dos Vinhedos.

Palavras-chave: Desenvolvimento; desenvolvimento regional; indicação de procedência; Vale dos Vinhedos; indicação geográfica.

\section{ABSTRACT}

This article aims to analyze the socio-economic development in the delimited area of Vale dos Vinhedos region, located in the cities of Bento Gonçalves, Garibaldi and Monte Belo do Sul, Rio Grande do Sul, Brazil, from the recognition of the geographical indication and the perspective of social actors involved in the process. It refers to a qualitative, descriptive research in a historical perspective, from the point of view of the involved subjects themselves, such as wine producers, managers of local associations, representatives of the public power and technicians who have formatted the process of recognition of wines' origin indication. The data were collected from questionnaires and interviews with the mentioned social actors. The results initially provided the concepts of development (local, endogenous), intellectual property and geographical indications, in order to ground this research, demonstrating the promotion of development in Vale dos Vinhedos by its region origin indication. In addition, this research analyzes the case of this region looking for showing the economic and social implications of this recognition about the development of Vale dos Vinhedos.

Keywords: Development; regional development; origin indication; Vale dos Vinhedos; geographical indication. 


\section{INTRODUÇÃO}

Este texto aborda de modo aprofundado o estudo do desenvolvimento regional sob a perspectiva do reconhecimento da indicação geográfica. Parte-se do pressuposto de que a indicação geográfica pode ser considerada um instrumento para alavancar o desenvolvimento territorial. Assim, analisa-se o case do Vale dos Vinhedos, localizado entre os municípios de Bento Gonçalves, Garibaldi e Monte Belo do Sul, no estado do Rio Grande do Sul, a primeira região brasileira a obter oficialmente tal reconhecimento.

O reconhecimento da indicação geográfica de um determinado produto num mercado globalizado, competitivo e cada vez mais exigente oportuniza, por meio de mecanismos como a denominação de origem (DO) ou indicação de procedência (IP), o crescimento socioeconômico de regiões, protegendo a qualidade e a procedência dos produtos ali elaborados, agregando valor a eles e conquistando novos mercados e consumidores.

Como se verá no decorrer deste estudo, a regulamentação das indicações geográficas se dá tanto em âmbito nacional quanto internacional, o que também pode ser visto como um facilitador para a inclusão dos produtos oriundos dessas regiões no mercado externo, fomentando seu desenvolvimento social e econômico, além de proteger juridicamente os produtores contra a concorrência desleal. Isso significa que o assunto envolve não apenas aspectos socioeconômicos, mas também alguns enfoques jurídicos e legais.

Assim, este estudo tem como objetivo analisar o caso de desenvolvimento socioeconômico da área delimitada da região do Vale dos Vinhedos, localizada nos municípios de Bento Gonçalves, Garibaldi e Monte Belo do Sul, no estado do Rio Grande do Sul, a partir do reconhecimento da indicação geográfica e da ótica de seus atores sociais envolvidos.

Para o alcance desse objetivo, a pesquisa se estrutura da seguinte forma: inicialmente, são abordados conceitos correlatos e apresentados alguns aspectos jurídicos e legais relevantes relacionados ao tema. Num segundo tópico são explicitados os procedimentos metodológicos utilizados para desenvolver esta pesquisa. No terceiro tópico, caracteriza-se a região e se explicita o processo de reconhecimento da IP. No último tópico, são expostos os resultados da análise, destacando aspectos econômicos e sociais, entraves, dificuldades e articulações desencadeadas na região do Vale dos Vinhedos.

\section{INDICAÇÃO GEOGRÁFICA COMO FATOR DE DESENVOLVIMENTO}

Muito se tem estudado sobre o tema desenvolvimento local/regional nas últimas décadas, abordando não apenas aspectos econômicos, mas integrando também fatores sociais e ambientais nessas análises. A vinculação predominante do desenvolvimento com crescimento econômico há muito está superada, porém ainda não se estabeleceu nas ciências sociais uma clara distinção entre esses dois conceitos. Furtado (1988, p. 45) explica que:

O conceito de desenvolvimento tem contribuído mais do que qualquer outro no sentido de promover uma maior aproximação entre as disciplinas da ciência social, separadas por um século de influência positivista. A óbvia ambiguidade deste conceito certamente não deixa de estar relacionada à sua fecundidade. Tendo se originado na área da ciência econômica, onde a ênfase recai sobre seus aspectos quantitativos, sobre a forma de crescimento, o conceito inevitavelmente ultrapassa tal contexto e penetra no domínio de outras disciplinas sociais, nos casos em que o crescimento não pode ser visualizado como um processo homotético, ou não pode ser entendido na ausência de um sistema de valores que o economista não tem condições de integrar em seu arcabouço conceptual. 
Na mesma linha de pensamento, Sachs (2004) salienta que o desenvolvimento econômico se distingue do crescimento econômico, porque o desenvolvimento vai além da mera multiplicação de riqueza material, enquanto o crescimento é uma forma necessária, mas não suficiente para alcançar a meta de uma vida melhor e mais completa para todos, visto que não amplia emprego, não reduz desigualdades e nem atenua a pobreza.

Para Boisier (2006), o conceito de desenvolvimento se encontra atualmente em transição entre a antiga concepção, que o assimilava à ideia de crescimento, associando-o às riquezas materiais, e a nova concepção, que o representa como um processo intangível, que está associado mais às atitudes do que às conquistas materiais propriamente ditas.

Nessa perspectiva, Fischer (2002) entende que o desenvolvimento é um conceito, ou melhor, uma rede de conceitos que está diretamente associada a adjetivos, como: "local, integrado e sustentável", não sendo possível falar em desenvolvimento local sem fazer referência a conceitos como pobreza e exclusão, participação e solidariedade, produção e competitividade. Dessa forma, percebe-se que o desenvolvimento é encarado como um processo sequencial e interdependente, compreendendo, ao mesmo tempo, processos compartilhados e resultados atingidos; visões de futuro ou utopias construídas por coletivos organizacionais e ações concretas de mudança.

Sob outro prisma, Amartya Sen (2000, p. 25), Prêmio Nobel de Economia, enfatiza que o desenvolvimento é um processo integrado de liberdades substantivas interligadas, afirmando que "as liberdades não são apenas os fins primordiais para o desenvolvimento, mas também os meios principais", ou seja, os indivíduos necessitam ter liberdades para fazer suas escolhas. Nesse sentido, o autor traz a concepção de desenvolvimento como liberdade, isto é, o progresso, a industrialização e as inovações tecnológicas expandem a liberdade humana; porém, para que isso ocorra, é necessário que o desenvolvimento se dê no âmbito social, humano, econômico, jurídico e cultural.

Enquanto no mundo acadêmico se ampliam e se aprofundam concepções sobre o desenvolvimento socioeconômico, no mundo pessoal ocorre um aumento da produção, do consumo e da competitividade entre os mercados, levando regiões e países a ajustarem seus sistemas produtivos, estimulando o aparecimento de uma nova organização do sistema das regiões (BARQUERO, 2001). Em outras palavras, apesar da hegemonia desse novo paradigma (de globalização da economia), emerge também, e com muita força, a concepção do desenvolvimento local/regional, propondo-se a valorizar a qualidade de vida da população, preservando o meio ambiente e as peculiaridades de cada região.

Para Barquero (2001), o desenvolvimento local está ligado ao processo de crescimento e mudanças estruturais, que são desencadeadas pela transferência de recursos das atividades tradicionais para atividades que valorizam a população local e melhoram sua qualidade de vida. No mesmo sentido, Siedenberg (2006) aponta que o termo "desenvolvimento local" está ligado intrinsecamente às mudanças sociais e econômicas que ocorrem na matriz produtiva de um determinado espaço geográfico, devendo-se levar em consideração que essas mudanças também envolvem ligações entre instituições públicas, estruturas empresariais e organismos sociais presentes na região.

Llorens (2001) argumenta que existem alguns componentes de iniciativas de desenvolvimento local, isto é, mais equilibrados territorialmente, impulsionando a geração de emprego e renda para enfrentar a pobreza e a marginalização, criando entornos institucionais econômicos, sociais, políticos e culturais para difundir as inovações, reorganizar as bases empresariais e implantar infraestruturas básicas, além de capacitar recursos humanos e criar sistemas de informações locais. 
No que diz respeito ao desenvolvimento regional, no meio rural especificamente ${ }^{1}$, um fator importante, de acordo com Sachs (2004) são as criações de associações, que evidenciam a concorrência sem excluir a cooperação, comumente denominadas de Arranjos Produtivos Locais (APL). Tais arranjos têm importância fundamental na criação de políticas públicas voltadas à transformação gradual dos pequenos produtores em microempresários.

A categoria "pequenos produtores" inclui todos os envolvidos em atividades de pequena escala realizadas fora do universo das empresas modernas. Essa categoria responde pela maioria dos postos de trabalho do setor econômico. Sachs (2004) postula que é necessário dar aos pequenos produtores a oportunidade de melhorar suas atividades, aperfeiçoando suas habilidades mediante treinamento, sendo que, com isso, aumentará nas áreas agrícolas a modernização e o estabelecimento de indústrias de processamento de biomassa. Sendo assim, a expansão dos serviços deve ocupar um lugar destacado no desenvolvimento rural, oferecendo muitas vagas para empregos não agrícolas e reduzindo a diferença social entre a cidade e o campo. A pluriatividade tende a se tornar uma palavra-chave para os agricultores e suas famílias (Ibidem, 2004).

Com base nessas considerações, pode-se afirmar que ações endógenas reforçam as potencialidades de territórios como o Vale dos Vinhedos, sobretudo quando se observa que as ações endógenas são articuladas, tanto pela sociedade quanto pelo Estado e pelo mercado, por meio da criação de políticas públicas, incentivos e investimentos, como também são apoiadas por uma legislação específica.

\footnotetext{
1 Cabe lembrar aqui que o chamado Vale dos Vinhedos se configura tipicamente como um meio rural, formado por parte de três municípios da Serra Gaúcha: Bento Gonçalves, Garibaldi e Monte Belo do Sul.
}

Porém, é necessário considerar que cada região possui sua história, sua cultura, seu patrimônio, além de características políticas e econômicas próprias. Por esse motivo, num processo de desenvolvimento regional não é possível utilizar ou procurar simplesmente transferir estratégias, planos e metodologias implementadas em outras regiões, visto que cada região é única. "Toda região que pretende constituir-se sujeito e não apenas objeto no novo cenário global precisa conhecer-se a si mesma, conhecer suas forças e fraquezas, potencialidades, oportunidades e ameaças" (SIEDENBERG, 2007, p. 11). Assim, pode-se então procurar o desencadeamento de estratégias que visem o desenvolvimento socioeconômico e a melhoria da qualidade de vida daquele território.

É nesse contexto que se cristaliza o conceito de desenvolvimento endógeno. Segundo Amaral Filho (1996, p. 37), desenvolvimento endógeno é

\begin{abstract}
um processo interno de ampliação contínua da capacidade de agregação de valor sobre a produção, bem como da capacidade de absorção da região, cujo desdobramento é a retenção do excedente econômico gerado na economia local e/ou a atração de excedentes provenientes de outras regiões. Este processo tem como resultado a ampliação do emprego, do produto, e da renda local ou da região, em um modelo de desenvolvimento regional definido.
\end{abstract}

Tal processo requer ainda uma capacidade de inovar e transformar o sistema socioeconômico vigente num território, uma capacidade de reagir aos desafios externos, à promoção da aprendizagem social e à habilidade de introduzir formas específicas de regulação social a nível local que favoreçam o desenvolvimento do território em questão. Nesse sentido, Barquero (2001, p. 39) salienta que:

O desenvolvimento endógeno propõe-se a atender às necessidades e demandas da população local através da participação ativa da comunidade envolvida. Mais 
do que obter ganhos em termos da posição ocupada pelo sistema produtivo local na divisão internacional ou nacional do trabalho, o objetivo é buscar o bem-estar econômico, social e cultural da comunidade local em seu conjunto. Além de influenciar os aspectos produtivos (agrícolas, industriais e de serviços), a estratégia de desenvolvimento procura também atuar sobre as dimensões sociais e culturais que afetam o bem-estar da sociedade.

Barquero (2001) ainda chama atenção para o fato de que, nos processos de desenvolvimento endógeno, três dimensões precisam ser consideradas:

Econômica, caracterizada por um sistema específico de produção capaz de assegurar aos empresários locais o uso eficiente dos fatores produtivos e a melhoria dos níveis de produtividade que thes garantem competitividade; uma outra sociocultural, na qual os atores econômicos e sociais se integram às instituiç̧ões locais e formam um denso sistema de relações, que incorpora os valores da sociedade ao processo de desenvolvimento; e uma terceira, que é política e se materializa em iniciativas locais, possibilitando a criação de um entorno local que incentiva a produção e favorece o desenvolvimento sustentável. (Ibidem, 2001, p. 42)

Também é necessário considerar que nos processos endógenos as possibilidades de desenvolvimento estão atreladas ao volume de capital social existente em uma determinada comunidade, ou seja, aos laços de solidariedade, confiança interpessoal e sistemas de participação social. O capital social permite a criação de redes de confiança e cooperação, propiciando diversos benefícios e recursos que podem ser ativados e utilizados.

O capital social facilita o compartilhamento de informações e conhecimento, além de reduzir os custos, devido às relações de confiança, cooperação, fatores socioculturais e objetivos comuns. Também melhora a coordenação de ações, dando maior estabilidade para as organizações, em virtude dos processos de tomada de decisões coletivas. O capital social propicia ainda conhecimento mútuo, aumentando a previsibilidade do comportamento dos agentes, o que leva a uma diminuição de comportamentos oportunistas dentro de uma comunidade, gerando maior comprometimento em relação ao grupo (LIN; COOK; BURT, 2001).

O capital social está relacionado à aprendizagem interativa e à cooperação, especialmente quando ele é concebido como um processo dinâmico de relações sociais em redes que estabelecem e constroem o conhecimento. Por esse motivo, ele é considerado um facilitador nas ações coletivas que geram arranjos produtivos articulados. Assim, "os recursos imateriais ou intangíveis, presentes nas redes sociais, quando direcionados para um esforço conjunto de desenvolvimento [...], propiciam a produção e a reprodução do conhecimento tácito, catalisando processos de inovação e difusão" (ALBAGLI; MACIEL, 2004, p. 2).

Nesse sentido, verifica-se que, em processos de desenvolvimento territorial, tanto as potencialidades latentes quanto as articulações endógenas e o capital social se tornaram peças fundamentais para a prosperidade e competitividade das comunidades e organizações. Todavia, para que processos de desenvolvimento de territórios com grande especificidade, como o caso do Vale dos Vinhedos, sejam desencadeados, é necessário, além da mobilização da região, a criação de políticas públicas e legislações específicas, visando proteger e fomentar tais características e especificidades. Um bom exemplo de tutela jurisdicional que visa contribuir para o desenvolvimento de uma determinada região é o reconhecimento da indicação geográfica².

2 É necessário considerar que "indicação geográfica" é, em termos jurídicos, um ramo do instituto da "propriedade industrial", instituído pela Lei Federal 9.279 (BRASIL, 1996), de 14 de maio de 1996, que regula direitos e obrigações relativas à propriedade industrial e ao registro de marcas e patentes, bem como os aspectos concernentes à indicação geográfica (em especial nos art. 176 a 182). 
A indicação geográfica não é um instituto novo. Para Bruch (2008), a origem das indicações geográficas se deu na evolução da história da humanidade, uma vez que já na antiguidade produtos eram relacionados aos seus locais de origem. Segundo Kakuta (2006, p. 7), existem relatos do século IV a.C., na antiga Grécia, que referem "os vinhos de Coríntio, de ĺcaro e de Rodhes", bem como em Roma, que referem o "mármore de Carrara e os vinhos de Falerne".

Todavia, a atual concepção de indicação geográfica, em especial a denominação de origem, teve início na Europa, onde produtores de vinhos costumavam designar o nome do vinho pela região onde este foi produzido. Essa designação se dava em decorrência de suas características, principalmente em virtude de fatores climáticos específicos. Mas a proteção jurídica a este instituto estreou, por assim dizer, em meados do século XIX, tendo a França como pioneira. De acordo com Rodrigues e Menezes (2000, p. 3), "quando os produtores das regiões francesas de Bourgogne e Bourdeaux foram convidados a serem os fornecedores oficiais de vinhos que seriam servidos em uma exposição internacional, a ser realizada em Paris". Diante dessa necessidade, e para assegurar que os vinhos do evento eram produzidos naquelas regiões, os produtores classificaram seus vinhos, e essa classificação é hoje a base da denominação de origem ${ }^{3}$.

Em virtude desse evento, outras regiões francesas e também alguns países europeus se interessaram em instituir mecanismos para proteger seus produtos, em especial os produtos vinícolas. Essa proteção visava garantir suas características e defender seus produtos dos concorrentes. A partir desse momento, iniciou-se a construção legislativa

\footnotetext{
3 A França foi o primeiro país a instituir um selo oficial para garantir e controlar a qualidade dos alimentos produzidos em seu país. O selo se chama Apelação de Origem Controlada $(A O C)$, que foi criado para regulamentar e proteger "o uso dos nomes geográficos que designam produtos agrícolas e alimentares" (KAKUTA, 2006, p. 10).
}

e administrativa para identificar e proteger as indicações geográficas sobre esses produtos (Ibidem, 2000). Atualmente, além da Europa, outras nações emergentes, como China e Índia, estão investindo no reconhecimento de novas indicações geográficas a fim de protegerem as origens de seus produtos, bem como garantirem a qualidade original (KAKUTA, 2006).

Segundo Brabet e Pallet (2005), a União Europeia instituiu em 1992 o Regulamento CEE n 2081/1992, tendo como objetivo proteger o uso dos nomes geográficos dos produtos agrícolas e alimentares, e essa regulamentação se estende por todos os Estados membros. A comunidade europeia conta atualmente com aproximadamente 4.900 indicações geográficas protegidas, sendo 4.200 de vinhos e bebidas espirituosas e 690 de outros produtos, como queijos, frutas, carnes, legumes e azeites (KAKUTA, 2006). Assim, fica evidente que os países europeus, em especial a França e a Itália, fomentam as indicações geográficas, visando proteger e divulgar as peculiaridades territoriais, agregando aos produtos um diferencial competitivo, com vistas a desenvolver uma determinada região, buscando preservar a cultura e a identidade da comunidade local (GURGEL, 2005).

No Brasil, a Lei $n^{\circ}$ 9.279, que instituiu as indicações geográficas (BRASIL, 1996), fez distinção entre IP e DO. Na concepção de Locatelli (2007, p. 229), o cerne da distinção entre IP e DO está na exigência desta última possuir "uma qualidade ou característica peculiar do produto ou serviço estritamente vinculada a sua origem", enquanto para a IP basta a "notoriedade da origem geográfica de um determinado produto ou serviço". Segundo o disposto no site do Instituto Nacional da Propriedade Industrial (INPI, 2014):

Indicação de Procedência - É o nome geográfico de um país, cidade, região ou uma localidade de seu território que se tornou conhecido como centro de produção, fabricação ou extração de determinado produto 
ou prestação de determinado serviço. É importante lembrar que no caso da Indicação de Procedência, é necessário apresentação de documentos que comprovem que o nome geográfico seja conhecido como centro de extração, produção ou fabricação do produto ou prestação do serviço.

Denominação de Origem - É o nome geográfico de país, cidade, região ou localidade de seu território, que designe produto ou serviço cujas qualidades ou características se devam exclusiva ou essencialmente ao meio geográfico, incluídos fatores naturais e humanos. Na solicitação da IG de Denominação de Origem, deverá ser apresentada também a descrição das qualidades e as características do produto ou serviço que se destacam, exclusiva ou essencialmente, por causa do meio geográfico, ou aos fatores naturais e humanos. (grifos no original)

O fato de a legislação brasileira ter incluído não apenas os produtos, mas também os serviços, como possíveis fatores determinantes da qualidade ou característica que vincula o meio geográfico garante o reconhecimento e a proteção de indicações geográficas peculiares decorrentes da mão-de-obra local, ou de fatores humanos, como os produtos artesanais.

O ordenamento jurídico brasileiro relativo à propriedade industrial criou condições e requisitos para o registro das indicações geográficas, além de outorgar ao Inpi as condições em que este registro se outorgará (RODRIGUES; MENEZES, 2000). O art. 182 e seu parágrafo único disciplinam essa matéria:

Art. 182. O uso da indicação geográfica é restrito aos produtores e prestadores de serviço estabelecidos no local, exigindo-se, ainda, em relação às denominações de origem, o atendimento de requisitos de qualidade.

§ Parágrafo único - O INPI estabelecerá as condições de registro das indicações geográficas. (BRASIL, 1996)
No que diz respeito ao registro das indicações geográficas no Brasil, este é de responsabilidade do Inpi, que deve respeitar os fluxos e trâmites regulamentados pela Resolução $n^{\circ} 75$, de 28 de novembro de 2000, e pelo Ato Normativo $n^{\circ} 134$, de 15 de abril de 1997, que instituem normas e procedimentos para a solicitação do registro (INPI, 2000). A resolução e o ato normativo estabelecem os procedimentos e os trâmites que os pedidos terão de se submeter até o deferimento ou não do reconhecimento da indicação geográfica.

Os requisitos necessários para a concessão de registro, tanto para a IP como para a DO, conforme dispõe a Resolução nº 75 (Ibidem), são:

a) Pedido referente a um único nome geográfico;

b) Requerimento no qual estejam designados o nome geográfico, a descrição e as características do produto ou serviço;

c) Instrumento que comprove a legitimidade da parte que solicita o registro;

d) Regulamento específico que discipline a utilização do nome geográfico;

e) Instrumento que comprove a delimitação da área;

f) Tratando-se de representações gráficas ou figurativas, as etiquetas pertinentes;

g) Em caso de pedido realizado por meio de procuradores, procuração com os poderes para tal;

h) Comprovante de pagamento da quantia exigida para o registro;

i) Elementos que comprovem a existência de uma estrutura de controle sobre os produtos e prestadores de serviços que estejam legitimados a utilizar o nome geográfico, bem como sobre os produtos ou serviços;

j) Elementos que comprovem que os produtores ou prestadores de serviços que estão estabelecidos na área delimitada para a indicação geográfica estejam efetivamente 
exercendo atividades de produção ou prestação de serviços.

Tratando-se de requisitos específicos para a denominação de origem, além dos requisitos de uso comum, o requerente deve apresentar a descrição de qualidade e características do produto ou serviço que se devam exclusiva ou essencialmente ao meio geográfico, incluindo os fatores humanos e naturais, além de apresentar a descrição do método ou processo de obtenção do produto ou serviço, que deve ser local, leal e constante (INPI, 2000).

No Brasil, as indicações geográficas ainda são um nicho a ser explorado, uma vez que são poucos os pedidos de registros requeridos e concedidos pelo Inpi, considerando que somente em 2002 houve o reconhecimento da primeira IP (Vale dos Vinhedos), e em 2010 o reconhecimento da primeira DO (arroz do Litoral Norte Gaúcho), ambos concedidos pelo Inpi (THAINES, 2012).

\section{PROCEDIMENTOS METODOLÓGICOS}

Visando dar conta do objetivo proposto nesta pesquisa (analisar o desenvolvimento econômico e social da região do Vale dos Vinhedos a partir do reconhecimento da indicação geográfica), adotou-se como principais procedimentos técnicos a pesquisa bibliográfica e documental, complementados por um trabalho de campo que consistiu na aplicação de questionários com base em roteiros semiestruturados. Por meio desses questionários foram coletados dados primários, informações e percepções junto a alguns produtores de vinhos da região do Vale dos Vinhedos, bem como informações de gestores da respectiva associação que deu origem ao empreendimento, representantes do poder público e técnicos que fomentaram o processo de reconhecimento da IP.

Nesse sentido, foi utilizada uma abordagem qualitativa para verificar a percepção dos entrevistados quanto aos novos mercados e às vantagens obtidas, além das implicações embutidas no processo após o reconhecimento da IP Vale dos Vinhedos (IPVV); quanto às implicações sociais e organizacionais da constituição de uma indicação geográfica; quanto às condições e aos requisitos; quanto aos entraves e/ou às dificuldades encontradas pelos atores para conseguir esse status; e também para explicar como as articulações ampliaram as formas de cooperação e fomentaram o desenvolvimento da região.

Dessa forma, esta pesquisa se insere no campo das ciências sociais, tendo por mote a análise de um processo histórico a partir dos próprios sujeitos, ou seja, das pessoas que "vivem o presente marcado pelo passado e projetando o futuro, num embate constante entre o que está dado e o que está sendo construído" (MINAYO, 1994, p. 13). Portanto, o estudo tem um caráter fenomenológico preponderante. Esse método não é dedutivo nem indutivo, o entendimento dos fatos se dá a partir da visão das pessoas que estão vivendo esses fatos e os experimentando, tendo, portanto, um caráter transcendental e subjetivo. Nesse método é utilizada a hermenêutica, cuja compreensão exige a leitura do contexto, em que "diários, bibliografias, relatos centrados no cotidiano, estudos de caso, observações, conteúdo de textos para análise são as principais fontes de dados para o pesquisador" (VERGARA, 1998, p. 13).

Utilizou-se a técnica de entrevista com os atores sociais envolvidos no processo de desenvolvimento, pois se refere à técnica mais pertinente quando o pesquisador quer obter informações a respeito do seu objeto, as quais permitam conhecer sobre atitudes, sentimentos e valores subjacentes ao comportamento, o que significa que se pode ir além das descrições das ações, incorporando novas fontes para a interpretação dos resultados pelos próprios entrevistadores (RIBEIRO, 2008, p. 141). Bauer e Gaskell (2000) compreendem que a entrevista pode fornecer uma informação contextual 
valiosa para explicar alguns achados específicos, principalmente em uma perspectiva histórica.

Conforme Rosa e Arnoldi (2006, p. 87), em relação às outras técnicas de questionários, formulários, leitura documentada e observação participativa, as entrevistas apresentam vantagens que podem aqui ser evidenciadas:

Permitem a obtenção de grande riqueza informativa intensiva, holística e contextualizada - por serem dotadas de um estilo especialmente aberto, já que se utilizam de questionamentos semiestruturados. Proporcionam ao entrevistador uma oportunidade de esclarecimentos, junto aos segmentos momentâneos de perguntas e respostas, possibilitando a inclusão de roteiros não previstos, sendo esse um marco de interação mais direta, personalizada, flexível e espontânea. Cumprem um papel estratégico na previsão de erros, por ser uma técnica flexível, dirigida e econômica que prevê, antecipadamente, os enfoques, as hipóteses e outras orientações úteis para as reais circunstâncias da investigação, de acordo com a demanda do entrevistado, propiciando tempo para a preparação de outros instrumentos técnicos necessários para a realização, a contento, da entrevista.

Ribeiro (2008) aponta os limitadores da técnica de entrevista: custo elevado; consumo de muito tempo na aplicação; sujeição à polarização do entrevistador; não garantia do anonimato; sensibilidade aos efeitos no entrevistado; características do entrevistador e do entrevistado; treinamento especializado que a técnica requer; questões que direcionam a resposta. Gil (1999, p. 11) acrescenta os seguintes limitantes:

a) a falta de motivação do entrevistado para responder as perguntas que the são feitas;

b) a inadequada compreensão do significado das perguntas;

c) o fornecimento de respostas falsas, determinadas por razões conscientes ou inconscientes; d) inabilidade, ou mesmo incapacidade, do entrevistado para responder adequadamente, em decorrência de insuficiência vocabular ou de problemas psicológicos;

e) a influência exercida pelo aspecto pessoal do entrevistador sobre o entrevistado;

f) a influência das opiniões pessoais do entrevistador sobre as respostas do entrevistado.

No entanto, como explicam Britto Júnior e Feres Júnior (2011, p. 243), todas essas limitações intervêm na qualidade da entrevista, mas muitas delas podem ser contornadas pelo entrevistador, visto que o sucesso dessa técnica depende fundamentalmente do nível da relação pessoal entre entrevistador e entrevistado.

\section{CARACTERIZAÇÃO DO VALE DOS VINHEDOS E O PROCESSO DE RECONHECIMENTO DA INDICAÇÃO DE PROCEDÊNCIA}

A região do Vale dos Vinhedos foi a primeira a ser colonizada pelos imigrantes italianos, a partir de meados de 1875. Ali, desenvolveu-se inicialmente uma agricultura de subsistência e também de produção de itens consumidos no Rio Grande do Sul. A região foi colonizada por imigrantes advindos das regiões de Trento e Vêneto, na Itália, que trouxeram suas heranças culturais, principalmente o cultivo de videiras e a produção de vinhos, e iniciaram o plantio de uvas para a produção de vinhos para consumo próprio (APROVALE, 2009).

A região do Vale dos Vinhedos está localizada na Serra Gaúcha, na encosta superior do nordeste do Rio Grande do Sul, que apresenta altitudes que variam de 200 até 742 metros. A região do Vale dos Vinhedos possui dois referenciais: um político-administrativo, que se refere ao Distrito do Vale dos Vinhedos, o qual pertence ao município de Bento Gonçalves; e outro que diz respeito à área 
delimitada da indicação geográfica, a qual engloba parte dos municípios de Bento Gonçalves, Garibaldi e Monte Belo do Sul. A geografia do local exerce considerável influência sobre as videiras, o que reflete na escolha das técnicas de cultivo e na arte da elaboração dos vinhos, fazendo com que estes possuam identidade própria, permitindo que não se repitam. As variações climáticas da região são semelhantes às de outras regiões mundiais produtoras de vinhos (DALCIN, 2008).

Pertencem ao Vale dos Vinhedos todas as terras cujo deságue se dá no Arroio Pedrinho, uma conjunção territorial que toma parte dos três municípios (APROVALE, 2009), totalizando uma área de aproximadamente 81 quilômetros quadrados (LOCATELLI, 2007). O Distrito Vale dos Vinhedos foi criado em 1990, passando ao município de Bento Gonçalves após a emancipação de Monte Belo do Sul. Ele está divido em linhas que, por sua vez, dividem-se em comunidades, nomeadas de acordo com a capela local ou conforme a numeração das terras entregues aos imigrantes. Atualmente, a formação das comunidades é a seguinte: Linha Leopoldina, composta pela
Capela Nossa Senhora das Neves, Capela das Almas, Capela da Glória e Santa Lúcia; Linha Graciema, composta pelas linhas 8 da Graciema, 15 da Graciema, 40 da Graciema e pela Gruta Nossa Senhora de Lourdes do Ceará; e, Linha Zamith, composta pela Capela da Santíssima Trindade (APROVALE, 2009), conforme pode ser visto na Figura 1.

Com o aumento do cultivo da uva, os produtores começaram a vender sua produção para grandes empresas e cooperativas da região. Entretanto, no início dos anos 1990, o setor vitivinícola sofreu uma grave crise, o que ocasionou um grande prejuízo para os produtores da região do Vale dos Vinhedos, uma vez que eles não tinham mais para quem vender sua produção. Com isso, os produtores buscaram novas estratégias para se manterem no mercado, o que os levou a se unirem em uma associação, a fim de encaminhar um processo de reconhecimento de indicação geográfica, que resultou na IPVV, instrumento que visa proteger a qualidade e a procedência dos produtos ali produzidos, com o objetivo de agregar valor aos produtos e conquistar novos consumidores.

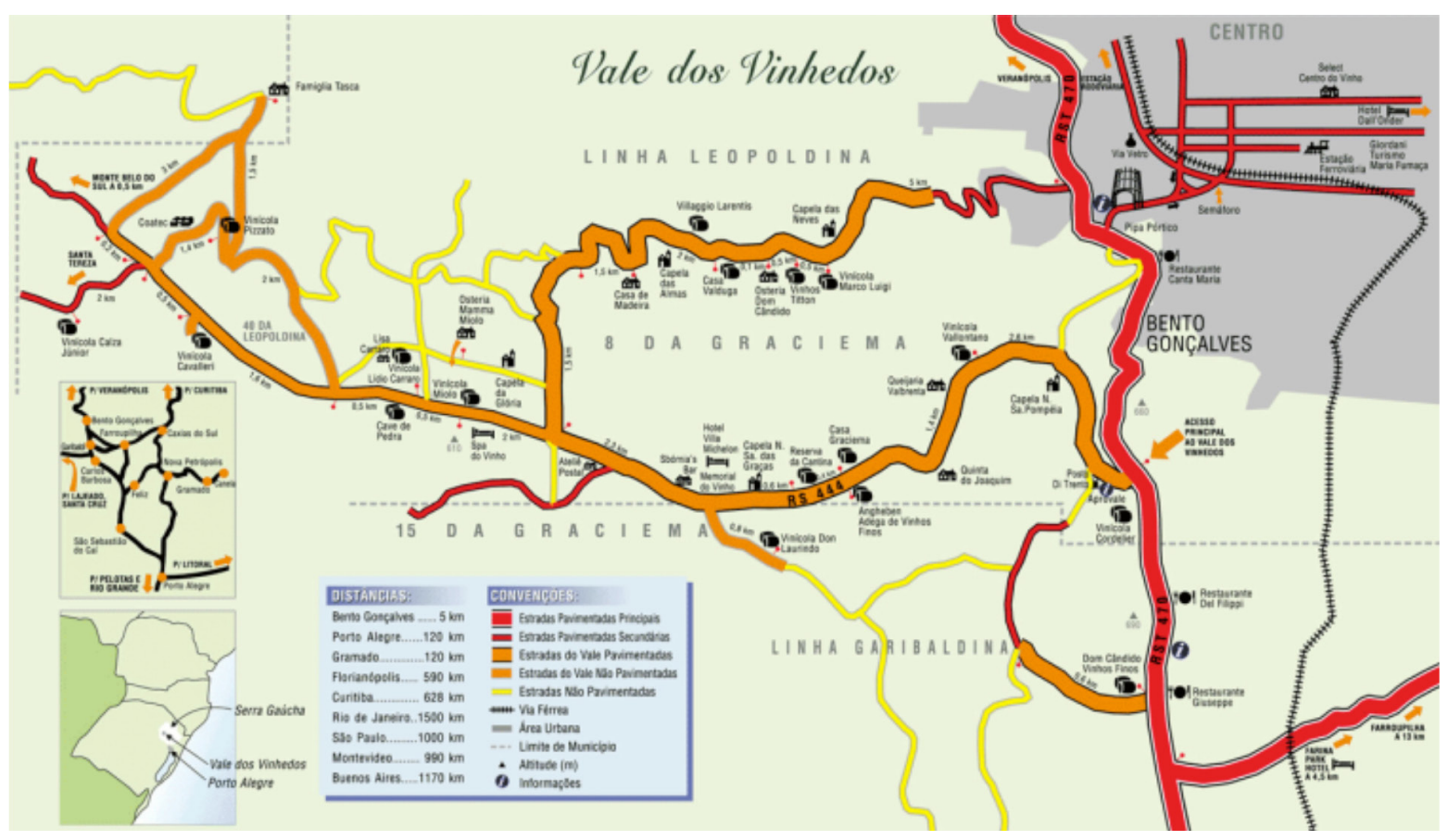

Figura 1 - Localização do Vale dos Vinhedos no município de Bento Gonçalves/RS

Fonte: Adaptado de Bento Gonçalves. 
O desencadeamento do processo de reconhecimento da IP está relacionado com a abertura da economia brasileira, principalmente após a assinatura do Tratado de Assunção em 1991, acordo que previa tarifa zero nas importações provenientes de países do Mercosul. Já nesse período, a Empresa Brasileira de Pesquisa Agropecuária (Embrapa) Uva e Vinho começou a visualizar um diferencial para a produção de vinhos na Serra Gaúcha, tendo por base, principalmente, os vinhos europeus. Visando dar respostas aos anseios dos produtores, esta unidade da Embrapa buscou alavancar elementos de competitividade que representassem um diferencial para os vinhos produzidos na região, sendo pioneira na discussão sobre o tema das indicações geográficas.

Para que o processo de reconhecimento se concretizasse, foi necessária, num primeiro momento, a sensibilização dos produtores da região sobre os benefícios e as potencialidades de se utilizar esse instrumento de propriedade intelectual. Num segundo momento, houve a necessidade de estudar o caso específico e demonstrar sua aplicabilidade aos produtores e à região, que não contava com uma legislação específica sobre o tema, pois o assunto era novo e deveria ser construído passo a passo. No início, seis pequenas vinícolas da região do Vale dos Vinhedos aceitaram e apoiaram o projeto da Embrapa - Uva e Vinho e da Universidade Caxias do Sul, organizando-se em uma associação, a Associação dos Produtores de Vinhos Finos do Vale dos Vinhedos (Aprovale) ${ }^{4}$.

Em 1995 já estavam disponíveis todos os dados e indicadores necessários. Em colaboração com a Universidade de Caxias do Sul, a região foi caracterizada e geograficamente delimitada, e uma

4 Segundo consta no site oficial da Aprovale, a associação conta atualmente com 26 vinícolas associadas e 43 empreendimentos de apoio ao turismo, entre hotéis, pousadas, restaurantes, artesanatos, queijarias, ateliês de artesanato e antiguidades e outros. Disponível em: <http://bit.ly/2tq2UVN>. Acesso em: 15 fev. 2017
Associação de Produtores e seu respectivo regulamento foram criados. Em 14 de maio de 1996, foi promulgada a Lei nº 9.279 (BRASIL, 1996), que regulou direitos e obrigações relativas à propriedade industrial, respaldando juridicamente o tema das indicações geográficas.

Após alguns ajustes necessários, em função da promulgação da lei, o projeto com o pedido de reconhecimento geográfico foi encaminhado ao Inpi em 1998, e sua aprovação ocorreu somente em 2002. O Vale dos Vinhedos foi a primeira região do país a conseguir uma indicação geográfica, a IPVV. Em 2007, a IPVV foi reconhecida pela União Europeia, o que facilitou a entrada e a comercialização dos vinhos produzidos na região no mercado europeu. Finalmente, em 2010, foi encaminhado ao Inpi o processo de DO, homologado em 2012 (INPI, 2017).

\section{IMPORTÂNCIA DA INDICAÇÃO GEOGRÁFICA NO DESENVOLVIMENTO DO VALE DOS VINHEDOS, NA PERCEPÇÃO DOS ATORES LOCAIS ${ }^{5}$}

Na opinião do representante do poder público (RPP), o reconhecimento oficial da IP e da DO obtidos pelo Vale dos Vinhedos em 2002 e 2012, respectivamente, tiveram um caráter estratégico no desenvolvimento da região:

A indicação de procedência ou indicação geográfica é
uma forma diferenciada de proteção a produtos, cujo
objetivo principal é o de distinguir a origem deste mesmo
produto através da identificação de sua área de produ-
ção, salvaguardando características locais, valorizando e
atestando qualidade. Em minha opinião, as indicações

5 Para preservar a identidade dos entrevistados, seus depoimentos serão identificados exclusivamente porsuas funções: representante do poder público (RPP); representante da Diretoria da Aprovale (RDA); empresário Associado da Aprovale (EAA). 
geográficas servem para agregar valor aos produtos e dar destaque a eles no mercado. Uma indicação de origem protege os produtos originados na região, beneficia os produtores que têm interesses comerciais e os sujeita ao cumprimento de regras de produção, bem como beneficia os consumidores que têm a garantia de autenticidade de origem e do padrão mínimo de qualidade dos produtos. (Depoimento do RPP)

O representante da diretoria da Aprovale (RDA) é ainda mais enfático na explicitação das vantagens decorrentes do reconhecimento da indicação geográfica:

A Indicação de Procedência Vale dos Vinhedos ajudou a abrir portas no exterior, pois nossas associadas podem exportar à União Europeia com a identificação da variedade e da safra, além da região produtora. Isto não é possivel a outros produtores nacionais que não têm direito ao uso da Indicação do Vale dos Vinhedos. O reconhecimento da Indicação de Procedência Vale dos Vinhedos, pela União Europeia, representa a elevação do vinho brasileiro a uma situação de igualdade com os vinhos de outras regiões mundiais, produtoras de vinhos de reconhecida qualidade. (Depoimento do RDA)

Em função do grande sucesso que o reconhecimento da IP trouxe ao setor vitivinícola das pequenas empresas localizadas no Vale dos Vinhedos, outros setores e empreendimentos passaram a incorporar a associação, tais como hotéis, pousadas, restaurantes, queijarias, artesanatos, agroindústrias e empreendimentos ligados ao enogastroturismo.

Especialmente por ser a primeira região brasileira a ter reconhecida uma indicação geográfica, o Vale dos Vinhedos ganhou notoriedade nacional e internacional, acarretando um aumento significativo no turismo. Tal aumento levou algumas empresas do setor hoteleiro e gastronômico a se instalarem na região, a fim de explorar esse novo nicho de mercado, como expõe um empresário associado da Aprovale:
Eu vi uma oportunidade de instalar aqui [no Vale dos Vinhedos] um complemento daquilo que já era um projeto vinícola e vitivinícola, que é a parte da gastronomia e da hotelaria. Então, nós aqui desenvolvemos esse projeto que denominamos Complexo Turístico Vale dos Vinhedos, que é mais que um hotel, tem uma série de composto. [...] Além disso, outros setores foram desenvolvendo, como é o caso da gastronomia, por ter vários restaurantes que vieram se instalar na região, de maneira em que, [...] em 10 anos, realmente houve uma modificação, para melhor, naturalmente, apesar das dificuldades enfrentadas pelos viti e vinicultores. Houve um progresso muito grande. (Depoimento do EAA)

Em relação ao desenvolvimento do turismo na região, o representante da diretoria da Aprovale (RDA) apresentou alguns dados consistentes:

O turismo é uma das armas mais importantes de todas as regiões vitivinícolas e não somos diferentes. Em pouco mais de 10 anos, crescemos mais de $240 \%$ no número de visitantes. Em 2001, recebemos 45.000 visitantes e, somente no ano passado, nos visitaram aproximadamente 200.000 turistas. Para isto, houve e continua havendo um crescimento de oferta na área hoteleira, de restaurantes e de serviços ligados ao enogastroturismo. (Depoimento do RDA)

Da mesma forma, para além da evolução do turismo, no que tange ao desenvolvimento social, pode-se verificar que os moradores da região enfatizam uma percepção muito positiva sobre a qualidade de vida e o desenvolvimento da região, o que também colaborou para a manutenção dessas pessoas em suas terras:

Quem visita o Vale dos Vinhedos [...] fica surpreendido com a qualidade de vida dos moradores, pelo padrão, não só econômico, mas também o grau de dedicação que os nossos moradores têm. (Depoimento do EAA) 
Não há dados estatísticos disponíveis que tratem especificamente da situação socioeconômica do Vale dos Vinhedos, eles estão disponíveis apenas para os municípios como um todo. Assim, não é possível aprofundar uma análise quantitativa sobre o desenvolvimento socioeconômico da região em específico. Porém, na avaliação que um gestor público local faz sobre a evolução de todo o empreendimento, transparecem muitos aspectos positivos:

Não tenho a menor dúvida em afirmar que o Vale dos Vinhedos cresceu muito. Mesmo antes da certificação, já se viam investimentos fortes, porém, a partir de 2002, com a indicação geográfica, o processo foi acelerado. Novos investimentos se sucederam, horizontes foram abertos, o Vale tornou-se referência, transpôs fronteiras e cresceu ainda mais, abrindo espaço, inclusive, para o turismo de negócios e de lazer. Considero desenvolvida a região [do Vale dos Vinhedos], pois tem índices de desemprego e pobreza muito baixos. Sua economia está em pleno desenvolvimento e, com a expansão da atividade turística, o Vale dos Vinhedos diversificou sua economia, sofrendo menos com as oscilações do mercado da uva e do vinho. (Depoimento do RPP)

Corroborando essa percepção, verifica-se que empresários da região também se manifestam favoravelmente sobre a trajetória do desenvolvimento local ao abordarem a questão da geração de emprego e renda, bem como outros aspectos, como pode ser visto nos depoimentos:

Na geração de emprego, todos esses empreendimentos, sejam hoteleiros, restaurantes, têm muitas implicações sociais. Realmente, quando nós, há 15 anos atrás, aqui [no Vale] ocupávamos exclusivamente a mão-de-obra local, hoje, para poder atender à demanda, é necessário lançar mão de grande maioria, de 60 a 70\% de mão-de-obra que vem de outras regiões. Nesse aspecto social e geração de emprego e renda, realmente, digamos, esse desenvolvimento [da região do Vale dos Vinhedos] propiciou, não só para a população local, mas para pessoas que vieram de outras regiões, enriquecer com seu trabalho. [...] isso aqui [o Vale dos Vinhedos], há 10 anos atrás não tinha nada; nem asfalto, a gente tinha, era estrada de chão. Então, o potencial que o Vale dos Vinhedos tem é infinito, hoje todos querem investir aqui. (Depoimento de EAA)

Como se percebe pelo teor dos depoimentos coletados entre os diversos atores (poder público, associação, empresários), a opinião sobre os benefícios decorrentes do reconhecimento da indicação geográfica do Vale dos Vinhedos é praticamente unânime. Entretanto, também é necessário considerar que a região detinha potencialidades latentes enquanto rota enoturística. A trajetória até o reconhecimento da IP teve que superar, inclusive, a ausência de uma legislação específica relacionada ao tema, pois as articulações começaram no início dos anos 1990 e somente em 1996 foi promulgada sua respectiva lei.

Outra dificuldade encontrada até a obtenção do reconhecimento da indicação geográfica foi a realização de um trabalho de convencimento dos produtores, procurando incutir neles a ideia de que a indicação geográfica poderia ser um instrumento interessante para o setor vitivinícola da região, visto que tal reconhecimento agrega um diferencial nos produtos produzidos na região.

Para que esse processo prosperasse e rendesse frutos, foi necessária a incorporação de novos conceitos na forma de produzir a uva e na elaboração do vinho, o que evidentemente demandou investimentos por parte dos produtores. Para o reconhecimento da IPVV, foi necessária uma revolução no processo produtivo, desde a reconvenção dos parreirais ${ }^{6}$

\footnotetext{
6 O chamado sistema de condução latada ou tradicional (videiras horizontais, em forma de teto), compromete a qualidade da produção, devido ao sombreamento dos cachos, à umidade demasiada e ao excesso de produção. O sistema de condução espaldeira (vertical) resulta numa diminuição da quantidade produzida, mas com um aumento da qualidade do produto, porém é recomendado mundialmente por pesquisas e assistências técnicas por ser a melhor forma para a produção de uvas viníferas.
} 
(do sistema latada para espaldeira), até a forma de elaboração dos vinhos, visando a qualidade.

Para a obtenção do reconhecimento da IPVV, foi necessária a criação de uma forte articulação, que contou com a cooperação de vários segmentos. O próprio processo de IP obriga os produtores/empresários a se mobilizarem para a criação de uma associação, sendo que o titular da indicação de procedência é a associação e não o produtor ou o prestador do serviço.

Na região do Vale dos Vinhedos, percebe-se que essas articulações e a cooperação se deram de maneira bem ampla, cujo processo contou com a parceria de vários segmentos, tais como Embrapa Uva e Vinho, Universidade de Caxias do Sul, produtores vitivinícolas e alguns empresários da região. Porém, os representantes do poder público (prefeituras da região) reconhecem que a participação do segmento em todo o processo foi ínfima, apenas "formalizando apoio por meio de um ofício para integrar o processo". Entretanto, depois de consolidado o processo,

o município contemplou o Vale dos Vinhedos com um Plano Diretor ${ }^{7}$ que impede uma expansão desenfreada e sem critérios, o que garante a identidade existente. O Vale também conta com uma Subprefeitura capaz de atender à demanda de solicitações, o que agiliza serviços e propicia uma ligação constante com o poder público. O Vale também dispõe de um Conselho Regulador, que avalia todo e qualquer projeto. Em nivel de Secretaria de Desenvolvimento Econômico, dispomos de uma Lei de Incentivos que nos propicia contemplar a classe empresarial com benefícios dos mais variados, tanto que a grande maioria dos empresários do Vale usufruiu das benesses dessa lei. (Depoimento do RPP)

7 É necessário ressaltar que esta é uma política específica implementada pelo município de Bento Gonçalves e abrange somente o Distrito do Vale dos Vinhedos e não a região da área delimitada. Nesse sentido, cada administração municipal é responsável por programas e projetos individuais que visam o desenvolvimento do Vale dos Vinhedos somente na área que pertence ao seu município.
Em que pese o árduo trabalho da Aprovale e de seus associados na divulgação do selo IPVV, tal divulgação ainda é deficitária, visto que a maioria dos atores, até mesmo algumas vinícolas instaladas na região, desconhece o significado do selo.

Como um dos objetivos do selo é diferenciar o produto produzido no Vale dos Vinhedos e agregar valor ao produto, as vinícolas estão sentindo que não está havendo esse reconhecimento, o que acarreta um entrave, já que as empresas estão investindo na aquisição desse selo e ainda não estão obtendo todo o retorno almejado.

Ainda não teve um retorno muito visível, pois não foi trabalhado o selo. Houve uma falha nossa, da Aprovale, e como a Aprovale somos nós, faltou maior exploração desse selo, por ser o primeiro do Brasil, além de ser reconhecido na Europa, por isso, faltou trabalho interno nosso. Eu uso bastante o selo, como empresa, mas como um todo, teve essa falha, isto é, a diferenciação [do produto] pela questão do selo. (Depoimento do EAA)

A percepção corrente entre os associados pertencentes ao setor vitivinícola do Vale dos Vinhedos é de que todos estão articulados e cooperando entre si, visando o desenvolvimento regional. Porém, alguns empresários instalados na região, que não são desse segmento, contestam essa percepção e afirmam que ainda existe necessidade de aperfeiçoar mecanismos de cooperação.

Com o objetivo de preservar a qualidade dos produtos e a confiança na marca é que existe o selo de controle outorgado pelo Conselho Regulador de Indicação Geográfica Vale dos Vinhedos, garantindo assim a procedência de origem. Somente podem ostentá-lo os vinhos elaborados com as uvas provenientes do Vale dos Vinhedos e engarrafados na sua origem. Além disso, os vinhos deverão ser aprovados em testes realizados por um grupo de especialistas composto por técnicos da Embrapa e da Aprovale. Portanto, a IPVV é garantia de origem com qualidade do Vale dos Vinhedos. 


\section{CONSIDERAÇÕES FINAIS}

A globalização e o declínio das fronteiras levaram a um aumento da competitividade nos mercados, desafiando regiões a se mobilizarem para equilibrar os efeitos desse processo em seus territórios, buscando fomentar a geração de emprego e renda a fim de valorizar e melhorar a qualidade de vida da população. Nesse sentido, verifica-se que o desenvolvimento de regiões passa pela criação de mecanismos que aumentem as potencialidades do território, mediante ações endógenas articuladas pela sociedade, pelo mercado e pelo Estado.

Buscando encontrar respostas para o desafio do desenvolvimento na região do Vale dos Vinhedos, técnicos da Embrapa - Uva e Vinho visualizaram na indicação geográfica um instrumento capaz de alavancar o desenvolvimento territorial, partindo do pressuposto que esse mecanismo gera desenvolvimento, beneficiando os produtores, consumidores e os produtos locais, por meio da qualificação dos produtos e da garantia de procedência.

Historicamente, outras formas de enfrentar o problema haviam sido experimentadas até então, como cooperativas ou associações de produtores. A tentativa de implantar a indicação geográfica obrigou os produtores a trabalharem de forma conjunta, tomarem decisões de forma conjunta e obedecerem a critérios de produção e de certificação pré-estabelecidos. Conseguir efetivar isso, de forma inovadora, na ausência de um respaldo jurídico formalmente estabelecido e num ambiente marcado por um sistema de produção concorrencial e individualizado, chega a ser surpreendente.

Hoje, não há a menor dúvida de que a indicação geográfica foi um fator que desencadeou diferentes processos de desenvolvimento socioeconômico no Vale dos Vinhedos, acarretando uma melhora significativa na qualidade de vida da população local, pois manteve a população na zona rural, valorizando seus imóveis (terras) e incentivando os produtores a investirem cada vez mais em seus negócios. Constata-se ainda que não apenas o setor vitivinícola, diretamente relacionado com a IP foi beneficiado com o reconhecimento, mas vários outros setores (hotelaria, turismo, artesanato, gastronomia etc.). Por outro lado, tal desenvolvimento trouxe para a região a especulação imobiliária, causando alguns transtornos, a ponto de ser necessária, para conter a expansão imobiliária desenfreada, a interferência do poder público, instituindo um plano diretor para o Distrito do Vale dos Vinhedos.

Constata-se, de modo geral, que o reconhecimento da IP e da denominação de origem do Vale dos Vinhedos auxiliou no fomento do desenvolvimento socioeconômico da região, tendo seu impacto refletido na economia, sob a forma de geração de emprego e renda, e na qualidade de vida da população local. Esse processo se tornou um indutor do desenvolvimento territorial local, visto que promoveu a interação entre o produto, o produtor, o consumidor e a paisagem da região, agregando outras atividades na cadeia principal, além de manter o homem em seu território. Conclui-se, portanto, que a indicação geográfica representa um novo instrumento capaz de impulsionar o desenvolvimento territorial, no seu aspecto social, econômico, político e cultural, pois agrega um diferencial aos produtos e serviços, dando notoriedade à região.

\section{REFERÊNCIAS}

ALBAGLI, S.; MACIEL, M. L. Informação e conhecimento na inovação e no desenvolvimento local. Ciência da
Informação, Brasília, DF, v. 33, n. 3, p. 9-16, set./dez. 2004. 


\section{REFERÊNCIAS}

AMARAL FILHO, J. Desenvolvimento regional endógeno em um ambiente federalista. Planejamento e Políticas Públicas, Brasília, DF, n. 14, 1996. Disponível em: <http:// bit.ly/2tpzPdl>. Acesso em: 28 jun. 2017.

APROVALE - Associação dos Produtores de Vinhos Finos do Vale dos Vinhedos. Indicação de procedência Vale dos Vinhedos. Disponível em: <http://bit.ly/2wDA6KF>. Acesso em: 20 nov. 2009.

BARQUERO, A. V. Desenvolvimento endógeno em tempos de globalização. Porto Alegre: UFRGS; FEE, 2001.

BAUER, M.; GASKELL, G. Pesquisa qualitativa com texto, imagem e som: um manual prático. Petrópolis: Vozes, 2000.

BENTO GONÇALVES (município). Vale dos Vinhedos. [20??]. Disponível em: <http://bit.ly/2tlT1lz>. Acesso em: 22 maio 2014.

BOISIER, S. Desenvolvimento. In: SIEDENBERG, D. R. Dicionário do desenvolvimento regional. Santa Cruz do Sul: Edunisc, 2006. p. 69.

BRABET, C.; PALLET, D. Os selos oficiais de qualidade dos alimentos na França e na Europa. In: LAGES, V.; LAGARES, L.; BRAGA, C. L. (Orgs.). Valorização de produtos com diferencial de qualidade e identidade: indicações geográficas e certificações para competitividade nos negócios. Brasília, DF: Sebrae, 2005. p. 19-41.

BRASIL. Lei no 9.279, de 14 de maio de 1996. Regula direitos e obrigações relativos à propriedade industrial. Diário Oficial da União, Brasília, DF, 15 maio 1996. Seção 1, p. 8353. Disponível em: <http://bit.ly/1zHQ1jc>. Acesso em: 23 maio 2014.

BRITTO JÚNIOR, A. F.; FERES JÚNIOR, N. A utilização da técnica da entrevista em trabalhos científicos. Evidência: olhares e pesquisa em saberes educacionais, Araxá, v. 7, n. 7, p. 237-250, 2011.

BRUCH, K. L. Indicações geográficas para o Brasil: problemas e perspectivas. In: PIMENTEL, L. O.; BOFF, S. O.; DEL'OLMO, F. S. (Orgs.). Propriedade intelectual: gestão do conhecimento, inovação tecnológica no agronegócio e cidadania. Florianópolis: Fundação Boiteux, 2008. p. 226-245.

DALCIN, M. S. Vale dos Vinhedos: história, vinho e vida. Bento Gonçalves: MSD Empreendimentos Culturais, 2008.

FISCHER, T. (Org.). Gestão do desenvolvimento e poderes locais: marcos teóricos e avaliação. Salvador: Casa da Qualidade, 2002.

FURTADO, C. Desenvolvimento. In: CAIDEN. G. E.; CARAVANTES, G. R. (Orgs.). Reconsideração do conceito de desenvolvimento. Caxias do Sul: Educs, 1988. p. 45-71.

GIL, A. C. Métodos e técnicas de pesquisa social. 5. ed. São Paulo: Atlas, 1999.

GURGEL, V. A. Aspectos jurídicos da indicação geográfica. In: LAGES, V.; LAGARES, L.; BRAGA, C. L. (Orgs.). Valorização de produtos com diferencial de qualidade e identidade: indicações geográficas e certificações para competitividade nos negócios. Brasília: Sebrae, 2005. p. 44-58.

INPI - Instituto Nacional da Propriedade Industrial. Resolução $n^{\circ}$ 75, de 28 de novembro de 2000. Estabelece as condições para o registro das indicações geográficas. Brasília, DF: Inpi, 2000. Disponível em: <http://bit.ly/2t1 NrIR>. Acesso em: 28 jun. 2017. Indicação geográfica. Brasília, DF: Inpi, 2014. 


\section{REFERÊNCIAS}

Lista das indicações de procedência concedidas.

Brasília, DF, 2017. Disponível em: <http://bit. ly/1SLQU5v>. Acesso em: 25 mar. 2017.

KAKUTA, S. M. et al. (Orgs.). Indicações geográficas: guia de respostas. Porto Alegre: Sebrae, 2006.

LIN, N.; COOK, K.; BURT, R. (Eds.). Social capital: theory and research. New York: Aldine de Gruyter, 2001.

LLORENS, F. A. Desenvolvimento econômico local: caminhos e desafios para a construção de uma nova agenda política. Rio de Janeiro: BNDES, 2001.

LOCATELLI, L. Indicações geográficas e desenvolvimento econômico. In: BARRAL, W.; PIMENTEL, L. O. (Orgs.). Propriedade intelectual e desenvolvimento. Florianópolis: Fundação Boiteux, 2007. p. 233-254.

Indicações geográficas: a proteção jurídica sob a perspectiva do desenvolvimento econômico. Curitiba: Juruá, 2008.

MINAYO, M. C. S. (Org.). Pesquisa social: teoria, método e criatividade. Petrópolis: Vozes, 1994.

RIBEIRO, E. A. A perspectiva da entrevista na investigação qualitativa. Evidência: olhares e pesquisa em saberes educacionais, Araxá, v. 4, n. 4, p. 129148, 2008.

RODRIGUES, M. A. C.; MENEZES, J. C. S. A proteção legal à indicação geográfica no Brasil. Revista da ABPI, Rio de Janeiro, n. 48, p. 3-20, 2000.
ROSA, M. V. F. P. C.; ARNOLDI, M. A. G. C. A entrevista na pesquisa qualitativa: mecanismos para a validação dos resultados. Belo Horizonte: Autêntica, 2006.

SACHS, I. Desenvolvimento: includente, sustentável, sustentado. Rio de Janeiro: Garamond, 2004.

SEN, A. Desenvolvimento como liberdade. São Paulo: Companhia das Letras, 2000.

SIEDENBERG, D. R. Desenvolvimento regional. In: SIEDENBERG, D. R. Dicionário do desenvolvimento regional. Santa Cruz do Sul: Edunisc, 2006. p. 71-73.

Desenvolvimento: ambiguidades de um conceito difuso. Revista Desenvolvimento em Questão, ljuí, v. 2, n. 3, p. 9-26, 2004.

Prefácio. In: DALLABRIDA, V. R.; BUTTENBENDER,

P. L. (Orgs.). Gestão, inovação e desenvolvimento: oportunidades e desafios para o desenvolvimento da região fronteira Noroeste. Santa Cruz do Sul: Edunisc, 2007. p. 9-17.

THAINES, A. H. Desenvolvimento regional sob a ótica do reconhecimento da indicação geográfica: o case do Vale dos Vinhedos. 2011. 160 f. Dissertação (Mestrado em Desenvolvimento) - Departamento de Economia e Contabilidade, Universidade Regional do Noroeste do Estado do Rio Grande do Sul, ljuí, 2011.

VERGARA, S. C. Projetos e relatórios de pesquisa em administração. 2. ed. São Paulo: Atlas, 1998. 